psychiatric disability such that the offence would have been committed even if the offender had become aware that he was certain to be caught and punished ?"

It is doubtful whether psychiatrists would show any greater measure of agreement among themselves by their answers in individual cases than they do now, but there would be the satisfaction of knowing that the source of the difficulty lay in the complexities of psychiatric illness and not in the dubious nature of the fundamental concept.-I am, etc., JAMES WARNER.

City of Coventry Child Guidance Centre.

\section{Single-handed G.P.s}

SiR,-Most general practitioners like myself must have been gratified and heartened to read the account of Dr. Davies's timely report to Council on the action of the G.M.S. Committee regarding G.P. remuneration (Supplement, November 16. p. 162).

As the pleas for increased rewards and incentives gather momentum, however, I do hope that our negotiators will take note of the position of the single-handed G.P. He is, of consequence, far more tied to his practice and therefore has less free time. works longer hours, and finds greater difficulty in arranging and getting holidays because of shortage of locums and expense in providing them. The financial load of providing secretarial or ancillary help must be far greater for the single-handed.

The group practitioner, on the other hand, has much more free time to devote to himself, his family, or to hospital, industrial. or other appointments, etc., and must find holidays longer. easier. and more certain. But, more important than this, especially when there is so much talk of the good doctor who provides a better service for his patients. is the fact that ancillary help in the form of nurse, receptionist, or secretary is much more readily available to group practitioners, as the cost of these per doctor must be one-third to one-sixth that prevailing on the single-handed doctor. Let us not forget that the very fact that he is singlehanded makes even more important his need for ancillary help and appointment systems.

Consequently, when devising new distribution schemes and considering possible capital provision for premises, etc., I do hope that the interests of singlehanded G.P.s will be borne in mind by our negotiators.-I am, etc..

Mitcham, Surrey. TREVOR SILVER.

\section{The Title of "Dr."}

SIR,- - The correspondence about the title "Doctor" is always of interest as it recurs from time to time.

The degree of Doctor of Medicine is, in the British Commonwealth. the highest degree granted by our universities in the Faculty of Medicine. It is obtainable only after the presentation of original work which has been deemed to constitute an advance in medical science. It is not lightly bestowed and is entirely different from the qualifying licences and diplomas in status. It would be ridiculous to permit everyone on the Medical Register to use the letters "M.D." or any other letters suggesting academic standing to which he or she is not entitled. The doctorates in other faculties are. one must assume, rather jealously protected. -I am, etc.,

$$
\text { “M.D., M.Ch.” }
$$

\section{Cancer and Date of Birth}

SiR,-Attention has recently been drawn $n^{1}$ to an observation made on lung cancer patients in Holland. In studying the distribution of 330 cases by year and month of birth, Dijkstra ${ }^{2}$ has found variations which he considers significant ; in particular, he notes an excess of cases born in February and March. From th:s observation he deduces an enhanced suspectibility to lung cancer in persons born in late winter. and he suggests that this may be due to an irreversible metaplasia of the lungs caused by a lack of vitamin A following birth, both human and cow's milk being deficient in this vitamin in late winter.

If generallv applicable to lung cancer, Dijkstra's observation regarding month of birth would clearly be of great interest. However. his sample is small, and the first essential is to repeat his survey on a larger scale.

A study is in progress which, when conp'ete, will provide information on the dates of birth of approximately 4.000 men and 800 worren dying with certified primary carcinomas of the lung in southern England during the period 1959-61. This sample will comprise roughly one-twentieth of all certified lung cancer deaths in England and Wales during these years. The analysis is at present complete in respect of the months of birth of 2.042 men dying in 1959 and 1960. and the results are shown in the Tab'e below. with Dijkstra's figures for comparison.

Distribution by Month of Birth of 330 Lung Cancer Cases in Holland (Diikstra's Series), and of 2.042 Men Dying of Lung Cancer in Southern England in 1959 and 1960

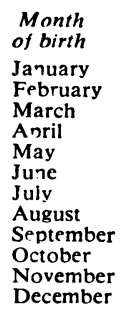

\begin{tabular}{|c|c|}
\hline 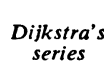 & $\begin{array}{l}\text { Male death } \\
\text { in Souther } \\
\text { England }\end{array}$ \\
\hline 23 & 170 \\
\hline $\begin{array}{l}36 \\
50\end{array}$ & $\begin{array}{l}169 \\
173\end{array}$ \\
\hline 29 & 173 \\
\hline 19 & $\begin{array}{l}162 \\
162\end{array}$ \\
\hline 22 & $\begin{array}{l}158 \\
158\end{array}$ \\
\hline $\begin{array}{l}21 \\
20\end{array}$ & $\begin{array}{l}158 \\
189\end{array}$ \\
\hline 26 & 185 \\
\hline $\begin{array}{l}28 \\
28\end{array}$ & 165 \\
\hline $\begin{aligned} 29 \\
27\end{aligned}$ & $\begin{array}{l}727 \\
168\end{array}$ \\
\hline & \\
\hline
\end{tabular}

All Months $. . \quad . . \quad 330$.. ${ }^{2.042}$ large sample do not support Dijkstra's observation. no significant variation between months being revealed.

We must conclude that there is at present no evidence that lung cancer in th's country is in any way related to month of birth. Speculations regarding the role of vitamin-A deficiency in the newborn as a cause of lung cancer, or of dried milk as a prophylactic. ${ }^{1}$ appear premature in the absence of such evidence.-I am, etc.,

Joan M. Davies.

\section{Department of Clinical Research,} the Institute of Cancer Research London S.W.3.

REFE

1 Lancet, 1963, 2, 1210. Dijkstra, B. K.' S., J. nat. Cancer Inst., 1963, 31,

\section{Tetanus Prophylaxis}

Sir,-Dr. Colleen A. Cox, Professor J. Knowelden, and Mr. W. J. W. Sharrard (November 30, p. 1360) are to be congratulated on three counts. They have, firstly, conducted excellent surveys on tetanus cases and reactions to tetanus antitoxin. Secondly, their paper is lucid. controversial, and contains helpful tables. And thirdly, they have had the courage to abandon antitoxin in the prophylaxis of tetanus. I believe that this policy may well be justifiable in an industral city like Sheffield: well-equipped and wellorganized accident departments can rapidly cope with accident cases from modern factories with industrial medical officers and experienced first-aid staff. Speed and efficiency ensure that an injured person can be examined, given antibiotics (when indicated), and operated on in the shortest possible time.

How very different is the plight of the casualty officer in a small country hospital when confronted by a farmer who, four days previously, ran a fork into his foot and arrives with manure still in his penetrating wound. It would take great courage to withhold tetanus antitoxin in such a case.

Time will tell whether the Sheffield experiment can succeed: I hope it will because every effort should be made to cut out antitoxin when antibiotics plus swift, efficient surgery will suffice to prevent tetanus. But I believe that circumstances do and will continue to occur where it is essential to give antitoxin (with all due precautions) in an attempt to offset tetanus. It is acknowledged that tetanus can occur (and kill) despite prophylactic antitoxin, but how many times has antitoxin saved a life?

Active immunization of more and more of the community is obviously the answer. It is interesting that in Sheffield the casualty department. recognizing its responsibility to complete active immunization after an injured person has been discharged, recalls its patients with reminders. It would be more interesting to learn how successfully this scheme operates. Some patients might prefer to have their own doctors complete the course. Some local authority clinics are anxious to help in this work. The chief worry about such divided responsibility would be ensuring that all three sets of records (hospital, general practitioner, and clinic) are completed and notified to each other. In any discussion on tetanus prophylaxis one always comes back to one of the keys to the whole problemrecords, personal and other.-I am, etc., 